\title{
Post-Traumatic Arthritis: The Role of Cytokine Levels in Serum and Synovial Fluid
}

\author{
Naser Sarafan ${ }^{1}$, Mohammad Fakoor ${ }^{1}$, Abdolhossein Mehdinasab ${ }^{1}$, Mohammad Bahadoram ${ }^{1,2}$, \\ Damoon Ashtary-Larky ${ }^{3,4}$, Hossein Mahdavi ${ }^{1} \&$ Fatemeh Javanmardi ${ }^{5}$ \\ ${ }^{1}$ Department of Orthopedic Surgery \& Trauma Research Center, School of Medicine, Ahvaz Jundishapur \\ University of Medical Sciences, Ahvaz, IR Iran \\ ${ }^{2}$ Medical Student Research Committee, Ahvaz Jundishapur University of Medical Sciences, Ahvaz, IR Iran \\ ${ }^{3}$ Department of Clinical Biochemistry, School of Medicine, Ahvaz Jundishapur University of Medical sciences, \\ Ahvaz, Iran \\ ${ }^{4}$ Health Research Institute, Diabetes Research Center, Ahvaz Jundishapur University of Medical sciences, \\ Ahvaz, Iran \\ ${ }^{5}$ Department of Biostatistics, School of Health, Ahvaz Jundishapur University of Medical Sciences, Ahvaz, Iran. \\ Correspondence: Hossein Mahdavi, Department of Orthopedic Surgery \& Trauma Research Center, School of \\ Medicine, Ahvaz Jundishapur University of Medical Sciences, Ahvaz, Iran. E-mail: Mahdavi-h@ajums.ac.ir
}

Received: August 27, 2016 Accepted: December 7, 2017 Online Published: December 20, 2017

doi:10.5539/gjhs.v10n1p166 URL: https://doi.org/10.5539/gjhs.v10n1p166

\begin{abstract}
Background and Objectives: Inflammatory processes play an important role in intra-articular fractures. The present study aimed to examine the relationship between chemerin, high-sensitivity C-reactive protein (hs-CRP), and Interleukin 17 (IL-17) serum and synovial fluid levels of osteoarthritis patients and individuals with intra-articular fractures.

Method: In this case-control study, all osteoarthritis patients and individuals with intra-articular fractures who visited the Imam Khomeini Orthopedic Clinic of Ahvaz were examined. Blood samples $(5 \mathrm{cc})$ were collected prior to surgery to measure chemerin Interleukin 17 , and hs-CRP serum levels. Synovial fluid samples $(2 \mathrm{cc})$ were collected during the surgery.

Results: Measuring the levels of IL-17, chemerin and hs-CRP indicated a significant statistical difference between the serum and synovial fluids of osteoarthritis patients, individuals with intra-articular fractures, and the control group $(p<.001)$. Post-hoc analyses showed statistically significant differences in all conditions except for hs-CRP levels between osteoarthritis patients and individuals with intra-articular fractures.

Conclusion: Discovering ways to stop or slow down osteoarthritis is a matter of great concern. The findings on osteoarthritis indicate diverse, complex, and multidimensional processes involving cytokines. Information on cytokines that effect diseases can help develop efficient therapy methods.
\end{abstract}

Keywords: intra-articular fractures, osteoarthritis, interleukin 17, chemerin, high-sensitivity c-reactive protein, serum, synovial fluid

\section{Introduction}

Adult intra-articular fractures of the distal radius include a distinct set of fractures which are related to post-traumatic arthritis and difficult to manage (Wojdasiewicz et al., 2014). Intra-articular fractures of the femur distal end pose difficult surgical challenges. In such cases, recovery is difficult and surgery is advised for desirable outcomes (Lieberthal et al., 2015). Intra-articular fractures of the distal end of the femur and proximal tibia are mainly caused by low-energy stumbling in elderly osteopenia patients. These fractures are signs of morbidity and usually require surgery (Hill et al., 2014). Distal radius fractures, on the other hand, are the most common type of fractures among individuals under 75 years old. To improve functionality and avoid long-term disability, treatments should be based on the patients' personal characteristics (Loi et al., 2016).

Inflammatory processes play an important role in the recovery of intra-articular fractures. From a molecular perspective, the recovery process is carried out by three kinds of signaling factors: inflammatory cytokines, 
Transforming Growth Factor-beta (TGF- $\beta$ ), and other growth and angiogenic factors (Gerstenfeld et al., 2003; Bahney et al., 2015). IL-1, IL-6, and TNF- $\alpha$ that signal the beginning of recovery processes, have been identified as important members of the first group (Gibon et al., 2016; Loi et al., 2016). These factors are not only produced by macrophages and inflammatory cells, but also by mesenchymal cells in the periosteoma. They also have a central role in down-stream responses to injuries by chemotactically influencing inflammatory factors, resulting in the stimulation of extracellular matrix synthesis and angiogenesis. Moreover, they cause the fibrogenic function of cells outside the injury area (Loi et al., 2016). The expression of these factors reaches its climax 24 hours after the fracture, ends in the cartilage production phase and increases again during remodeling (Chubinskaya \& Wimmer 2013; Loi et al., 2016). On the other hand, severe articular trauma can cause osteoarthritis. One study estimated about 21 million Americans to have osteoarthritis symptoms, 12\% of whom had post-trauma arthritis due to post-trauma etiology (Vaananen et al., 2014).

Osteoarthritis is an articular disease in which inflammatory and cartilage-destructive mediators are released into the synovial fluid from articular tissues (Kapoor et al., 2011). It is known that osteoarthritis is followed by the destruction of the subchondral bone cartilage and the remodeling and inflammation of the synovial membrane; however, its etiology and the factors triggering it are less studied. Inflammations caused by articular trauma may bring about other articular diseases. Following articular injury, the level of inflammatory cytokines in the synovial fluid increases. Previous studies reported levels of Interleukin 1 and TNF- $\alpha$ to have reached their climax 24 hours after injury (Hui et al., 2012; Lieberthal et al., 2015). These levels remain high for weeks and even months after trauma (Catterall et al., 2010; Olson et al., 2014; Christiansen et al., 2015). Based on clinical observations, cartilage derived biomarkers increase significantly a month after knee injury (Kramer et al., 2011; Konttinen et al., 2012). This shows that significant cartilage damage takes place weeks after the trauma, hence early intervention can effectively prevent long-term articular destruction (Imamura et al., 2015). Previous research has shown that cytokines other than IL-1 and TNF, might be involved in osteoarthritis and can thus be considered for recovery purposes (Haseeb \& Haqqi, 2013). Researchers of pathogenesis osteoarthritis have showed interest in the IL-17 family, a cytokine group with inflammatory effects that includes six members acting through five receptors (Pawlowska et al., 2009; Fahy et al., 2015). Main articular cells affected by IL-17 are chondrocytes and FLSs which express the IL-17 receptor (Lubberts et al., 2000).

Chemerin is a passive $(18 \mathrm{kDa})$ chemo-attractant adipokine activated by posttranslational C-terminal cleavage (Luangsay et al., 2009; Inci et al., 2016). In-vitro chemerin exogenous stimulates angiogenesis through cell proliferation, endothelial migration, and capillary tube formation which are all basic stages of angiogenesis development (Vermi, Riboldi et al., 2005). It is worth mentioning that chondrocytes express chemerin and its receptors and that IL-1 $\beta$ can increase the chemerin expression rate (Sharif et al., 2000; Jiang; 2013; Greene \& Loeser, 2015).

The present study was carried out to find the effect of inflammatory factors such as hs-CRP, IL-17, and chemerin on osteoarthritis and articular fractures to identify other potential factors affecting these fractures, and to compare healthy individuals with those experiencing intra-articular fractures.

\section{Method}

\subsection{Design and Participants}

This study was conducted on 60 patients with osteoarthritis, intra-articular fractures and healthy persons. All osteoarthritis patients or individuals affected by intra-articular fractures who visited Imam Khomeyni Orthopedics Clinic, Ahvaz, Iran, participated in this case-control study. Patient eligibility was confirmed by the hospitals orthopedists. Ethical considerations were addressed by following the guidelines of the Ethical Committee of the Ahvaz University of Medical Sciences and obtaining the patients' written consent prior to the study.

\subsection{Inclusion Criteria}

All participants had to be above 40, have endured knee pain for at least three months, and show degenerative M.R.I. symptoms. Evaluations were also carried out during surgery.

\subsection{Exclusion Criteria}

Patients with prior knee surgery or a history of knee-joint injuries caused by exercise or trauma as well as those who were taking anti-inflammatory drugs (e.g., Corticosteroids), those showing inflammation-related symptoms, diseases of the immune system or joints warm symptoms were excluded from the study.

\subsection{Data Collection}

Full details of the study were explained to participants who had all undergone knee-joint surgery as part of their 
therapy. Synovial fluid was collected under the supervision of orthopedists who took all required precautions to prevent common infections that occur during surgery or subsequent therapy. Participants were later interviewed and a questionnaire was given to them to collect general information regarding their age, gender, physical activity, smoking habits, dietary supplements and drugs (such as antioxidants or fish-oil taken more than 1 gr per day), weight-loss diets, medical history and diabetes. Blood samples $(5 \mathrm{cc})$ were collected prior to surgery to measure serum levels of Chemerin, Interleukin 17, and high-sensitivity C-reactive protein. Synovial fluid samples (2 cc) were also collected during the surgery. Immediately after each step, blood samples were centrifuged in $3000 \mathrm{~g}$ for 5 minutes to extract the serum which was then kept in $80^{\circ} \mathrm{C}$ until next usage. Heparinized synovial fluid (SF) samples were obtained from subjects. All samples were stored frozen at $-808 \mathrm{C}$ until analysis. ELISA (Enzyme-Linked Immunoassay) was used to determine plasma and synovial fluid levels.

\subsection{Statistical Analysis}

Categorical data were reported by frequency and percentage and quantitative continuous data was indicated by mean \pm SD. A one-way ANOVA was performed to comare three groups, also post-hoc Tukey test was utilized for investigating differences the control and test groups. Additionally, chi square analyses and ANOVA were performed to assess if the group matched in.demographic variables. Statistical analyses were performed by using SPSS18 software (SPSS Inc., Chicago, IL, USA.). P - values less than 0.05 were considered as the level of significancy.

\section{Results}

\subsection{IL-17}

As figure 1 shows, the amount of serum IL-17 was significantly different from the synovial fluid IL-17 for the osteoarthritis, intra-articular fracture, and control groups $(\mathrm{p}<.001)$. The one way ANOVA showed that sample type (fluid), group, and sample type-group interactions had a significant effect on IL-17 $(p<.001)$. Tukey post-hoc tests indicated a significant difference between the osteoarthritis and the control groups $(p<.001)$, the intra-articular fracture and the control groups $(\mathrm{p}<.05)$, and the osteoarthritis and intra-articular fracture groups $(\mathrm{p}$ $<.001$ ). Also there was no significant difference between demographic characteristic (e.g. age and gender) of study participants in three intervention groups (Table 1).

Table 1. Baseline characteristics of study participants in different groups

\begin{tabular}{llllll}
\hline \multicolumn{2}{l}{ Groups Variables } & Intra-Articular & Osteoarthritis & Control & P Value \\
\hline Age & & $34.5 \pm 7.02$ & $36.3 \pm 9.34$ & $32.5 \pm 10.35$ & 0.26 \\
\multirow{2}{*}{ Gender } & Male & $9(45 \%)$ & $8(40 \%)$ & $9(45 \%)$ & 0.71 \\
& Female & $11(55 \%)$ & $12(60 \%)$ & $11(55 \%)$ & \\
\hline
\end{tabular}

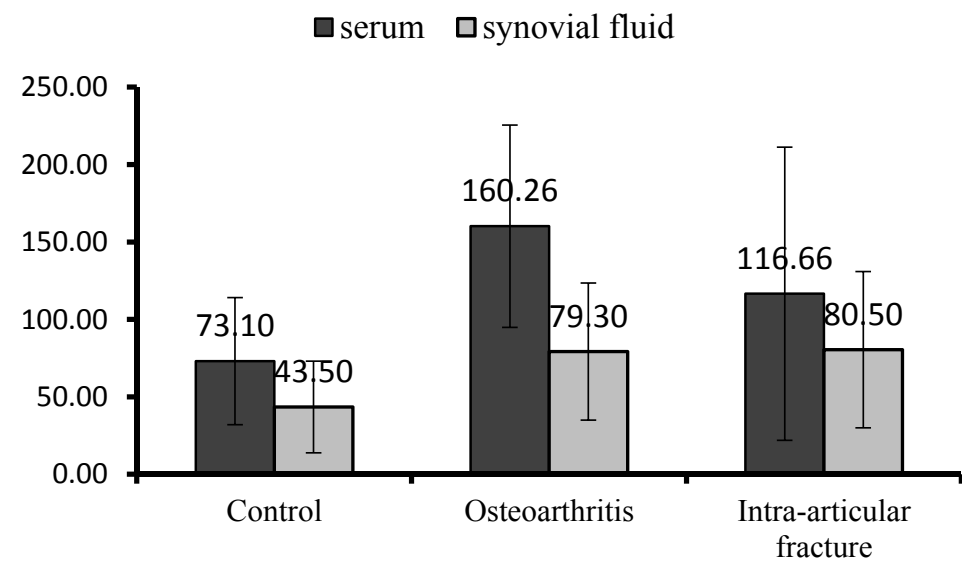

Figure 1. Comparison of the three groups for Interleukin 17. Mean values for synovial fluid and serum were 80.56 \pm 50.4 and $116.66 \pm 94.7$ for the intra-articular fracture group $(p<.001)$. For the osteoarthritis group, the mean values for synovial fluid and serum were $79.38 \pm 44.3$ and $160.26 \pm 65.3$, respectively $(p<.001)$. Regarding the control group, the mean values for synovial fluid and serum were $43.58 \pm 29.6$ and $73.1 \pm 41.08$, respectively ( $p$ 


\subsection{Chemerin}

As indicated by Figure 2, serum chemerin was significantly different from synovial fluid chemerin for the osteoarthritis, intra-articular fracture, and control groups $(p<.001)$. The ANOVA showed that sample type (fluid), group, and sample type-group interactions significantly affected chemerin $(p<.001)$. Tukey post-hoc tests indicated a significant difference between the osteoarthritis and the control groups $(p<.001)$ and the intra-articular fracture and the control groups $(p<.001)$. The osteoarthritis and intra-articular fracture groups, however, did not show any significant difference $(p>.05)$.

$\square$ serum $\square$ synovial fluid

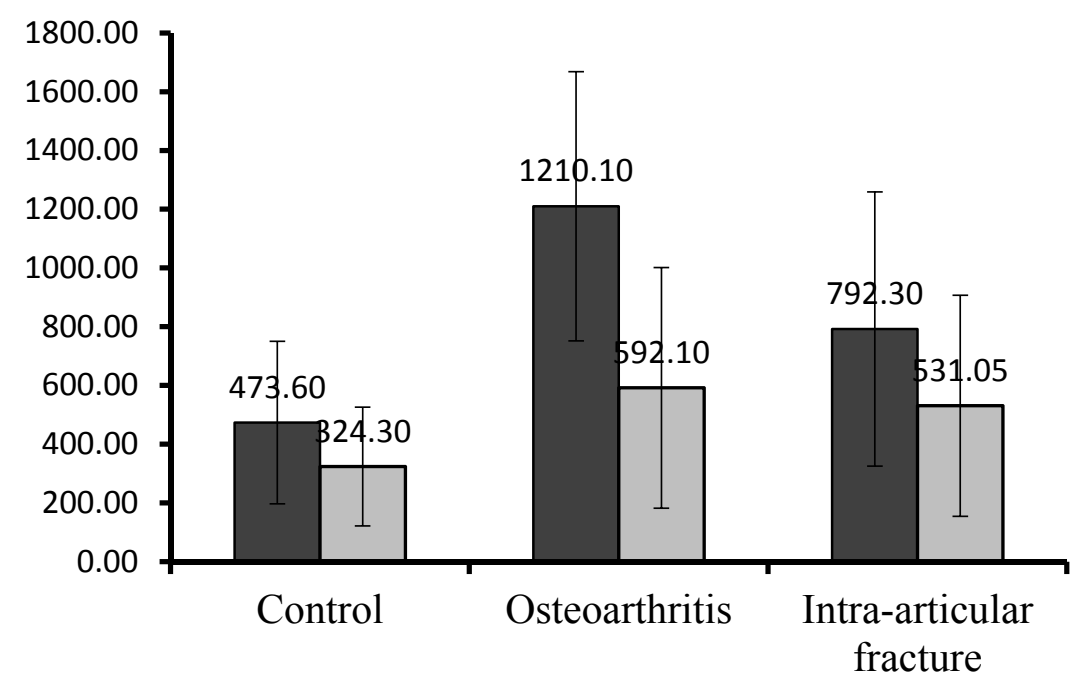

Figure 2. Comparison of the three groups for chemerin. Regarding the intra-articular fracture group, the mean values for synovial fluid and serum were $531.05 \pm 376.36$ and $792.31 \pm 466.7$, respectively $(p<.001)$. For the osteoarthritis group, the mean values for synovial fluid and serum were 592.09 \pm 409.8 and 1210.10 \pm 458.2 , respectively $(p<.001)$. AS for the control group, the mean values for synovial fluid and serum were $324.39 \pm$ 202.1 and $473.63 \pm 276.9$, respectively $(p<.001)$

\section{3. $H s-C R P$}

As figure 3 indicates, serum Hs-CRP was significantly different from that of the synovial fluid for all three groups $(p<.001)$. The ANOVA showed that sample type (fluid), group, and sample type-group interactions had a significant effect on Hs-CPR $(p<.001)$. Tukey post-hoc tests indicated a significant difference between the osteoarthritis and the control groups $(p<.001)$ and the intra-articular fracture and the control groups $(p<.001)$. The osteoarthritis and intra-articular fracture groups did not show any significant difference $(p>.05)$. 
$\square$ serum $\square$ synovial fluid

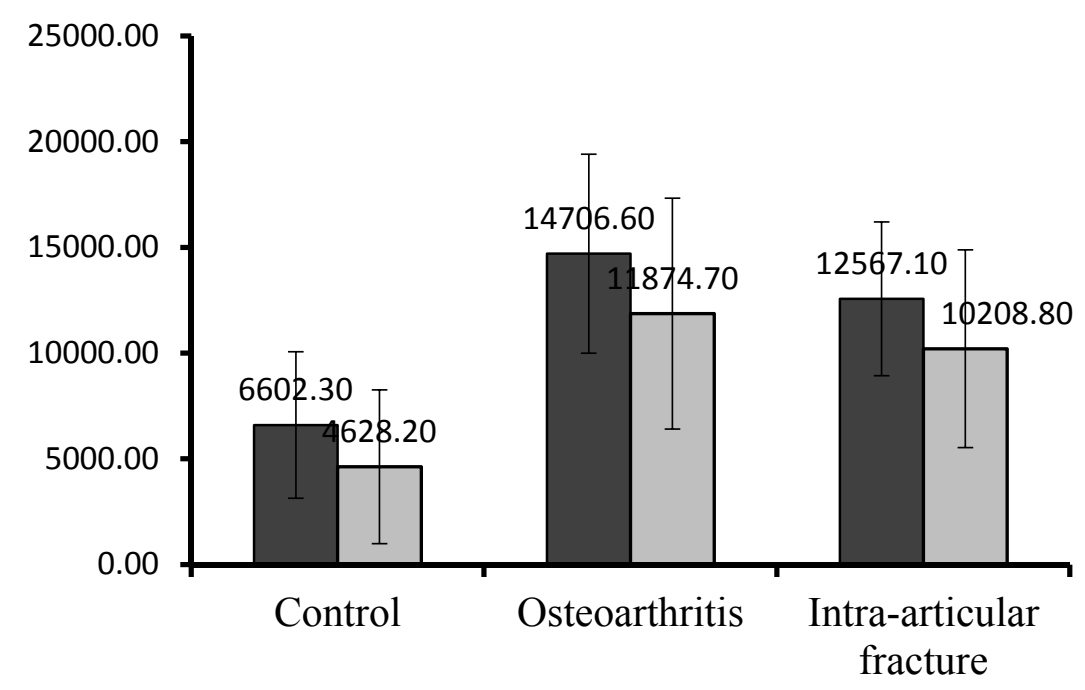

Figure 3. Comparison of the three groups for Hs-CRP. Regarding the intra-articular fracture group, the mean values for synovial fluid and serum were $8903.95 \pm 5538.2$ and $11292.02 \pm 5217.5$, respectively $(p<.001)$. For the osteoarthritis group, the mean values for synovial fluid and serum were $1187.74 \pm 5461.1$ and $14706.65 \pm$ 4708.1 , respectively $(p<.001)$. As for the control group, the mean values for synovial fluid and serum were $4628.21 \pm 3637.2$ and $6602.30 \pm 3465.1$, respectively $(p<.001)$

\section{Discussion}

The present study aimed at investigating the differences between serum and synovial fluid levels for chemerin factors, high-sensitivity C-reactive protein, and IL-17in osteoarthritis patients and individuals with intra-articular fractures. The results indicated significant statistical differences between chemerin levels, high-sensitivity C-reactive protein, and IL-17in serum and synovial fluids of osteoarthritis patients, intra-articular fracture patients, and healthy individuals.

Osteoarthritis is one of the most common chronic diseases in middle-age and elderly populations (Ruiz-Romero \& Blanco, 2010). The specific pathogen that causes osteoarthritis is still unknown, but it is thought to be related to trauma, strains, and the immune system responses. Biological aspects affecting cytokines in the synovial fluid and the articular cartilage have recently been studied due to the fact that Cytokines are important factors for treating and preventing osteoarthritis (Kapoor et al., 2011). IL-17has also been widely researched on pathogens and the treatment of multiple sclerosis (Kallaur et al., 2013; Elain et al., 2014; Sexton et al., 2014), systemic lupus erythematosus (Onishi \& Gaffen, 2010; Tanasescu et al., 2010), inflammatory bowel disease (Yu et al., 2012; Katz et al., 2014), and psoriasis (Raychaudhuri, 2013; Chiricozzi, 2014). Nevertheless, its relationship with osteoarthritis needs to be studied further.

The IL-17 family plays an important role in autoimmune diseases, hence the precise regulation of this cytokine can prevent inflammation. Previous research has shown that inflammatory responses in T-cells, epithelial, endothelial, and fibroblasts may affect the expression of IL-17, which can in turn, regulate chronic inflammations and host defenses causing tissue injury and autoimmune effects (Singh et al., 2014; Reinert-Hartwall, Honkanen et al., 2015). Many studies have shown that this cytokine is pre-expressed in rheumatoid arthritis (RA) patients. IL-17 can destroy collagen and weaken the bones in-vitro (Tanabe \& Yamashita, 2014; Roeleveld \& Koenders, 2015). Such neutralization of this cytokine or its receptors was shown to decrease arthritis symptoms in a rat model. IL-17 deficiency was also shown to protect the host against arthritis-related collagen damage in a rat model, and IL-17 gene therapy was shown to intensify it (van Baarsen et al., 2014; Zheng et al., 2014). It can be concluded, therefore, that IL-17 in RA patients might cause both inflammation and bone-destruction. This cytokine can also help improve cartilages, synovial cells, macrophages, and osteocytes, which can, in turn, result in the production of inflammatory cytokines (e.g., TNF-A, IL-1b). IL-17 can also stimulate several chemokines which cause neutrophil, macrophage, and lymphocyte aggregation in synovial membranes, ultimately resulting in severe articular injury (Hu et al., 2014; Wojdasiewicz et al., 2014). 
The present study found a direct relationship between the level of IL-17 in the synovial fluid of patients with osteoarthritis and articular fractures. Based on this finding, this cytokine might be considered as a new potential biomarker used to diagnose increased osteoarthritis side effects.

Yang et al., studied the existence of auto-antibodies against IL-17 and their relationship with disease activity in 60 RA patients, 72 osteoarthritis patients and 61 healthy individuals. Their findings indicated that antibody increase in response to IL-17 was directly related to the disease activity of those patients. Such evidence suggests that antibodies against IL-17 may play a protective role against the pathogens of such diseases (Yang et al., 2015). Liu et al., studied the role of IL-17 levels in the synovial fluid and its relationship with knee-arthritis intensity. They concluded that IL-17 might play an important role in osteoarthritis pathogens and controlling it can, therefore, delay osteoarthritis pain (Liu et al., 2015).

Chemerin includes pre-inflammatory mediators whose role has been studied in joint inflammation and cartilage destruction in-vitro. Most studies regarding the presence of this substance in the synovial fluid have focused on the role of their pathogens. The findings of the present study suggest a statistically significant difference between serum level and synovial fluid chemrin in osteoarthritis patients, individuals with intra-articular fractures, and healthy individuals. Huang et al. studied the relationship between serum and synovial fluid chemerin levels in 124 knee-arthritis patients and 76 healthy individuals. They concluded that chemerin level may have a role in the pathophysiology and disease progression (Huang et al., 2012).

Proteolytic enzymes have been shown to activate chemerin. These enzymes increase if inflammation occurs. Chemerin belongs to an extensive adipokine family. These kinases are mediators identified as cartilage-destructive pathogens (Zhuo et al., 2012). Valcamonica et al., studied synovial fluids chemerin levels in patients with different articular diseases including osteoarthritis, RA, and psoriatic arthritis. Their study suggests similar synovial fluid and serum chemerin levels the three diseases (Valcamonica et al., 2014). The present study, however, found statistically significant differences between synovial fluid and serum chemerin levels for the three groups osteoarthritis patients, individuals with intra-articular fractures, and healthy individuals.

Chemerin is also a chemotactic agonist considered to be a ligand for ChemR23 which is expressed on macrophages and dendritic cells. By activating FLSs through attachment to ChemR23, chemerin plays the role of a pathogen in RA (Herenius et al., 2013) and osteoarthritis (Mariani and Roncucci 2015) patients.

Evidence shows that osteoarthritis progression is accompanied by inflammation. Although hs-CRP is an index of systemic inflammation that increases in osteoarthritis patients, research findings show contradictory results. Jin et al., went through a systematic literature review and conducted a meta-analysis to study the relationship between serum hs-CRP levels and osteoarthritis. They found that low-grade systemic inflammation may play a more prominent role compared to radiography changes of osteoarthritis symptoms (Jin et al., 2015). Another study by Smith et al., showed that in addition to its role in inflammation mechanisms resulting in osteoarthritis progression, hs-CRP can be considered as a variable that can predict this disease.

\section{Conclusion}

Presently, researchers are looking for ways to block or slow down the progression of osteoarthritis. To this aim, certain methods are used to infiltrate intracellular transport routes that play a vital role in the inflammation processes. Research on inflammatory and anti-inflammatory cytokines is still in progress. Findings related to osteoarthritis indicate diverse, complex, and multidimensional processes at work that involve cytokines. Such information can help researchers develop efficient methods to deal with this disease.

\section{Authors' Contribution}

All authors passed four criteria for authorship contribution based on recommendations of the International Committee of Medical Journal Editors. Naser Sarafan, Mohammad Fakoor and Abdolhossein Mehdinasab designed the protocol. Mohammad Bahadoram, Hossein Mahdavi and Damoon Ashtary-Larky developed the protocol and performed it. Critical revision of the manuscript for important intellectual content was performed by Mohammad Bahadoram. Analysis of data was performed by Fatemeh Javanmardi.

\section{Ethical Issues}

This study was approved by the Ethics Committee of Ahvaz Jundishapur University of Medical Sciences, (Approved ethical code: IR.AJUMS.REC.1394.35).

\section{Conflict of Interest}

The authors declare that there is no conflict of interests regarding the publication of this paper. 


\section{References}

Bahney, C. S., Hu, D. P., Miclau, T. 3rd, \& Marcucio, R. S. (2015). The multifaceted role of the vasculature in endochondral fracture repair. Front Endocrinol (Lausanne), 6, 4. http://dx.doi.org/10.3389/fendo.2015.00004

Catterall, J. B., Stabler, T. V., Flannery, C. R., \& Kraus, V. B. (2010). Changes in serum and synovial fluid biomarkers after acute injury (NCT00332254). Arthritis Res Ther, 12(6), R229. http://dx.doi.org/10.1186/ar3216

Chiricozzi, A. (2014). Pathogenic role of IL-17 in psoriasis and psoriatic arthritis. Actas Dermosifiliogr, 105(Suppl 1), 9-20. http://dx.doi.org/10.1016/S0001-7310(14)70014-6

Christiansen, B. A., Guilak, F., Lockwood, K. A., Olson, S. A., Pitsillides, A. A., Sandell, L. J., ... Haudenschild, D. R. (2015). Non-invasive mouse models of post-traumatic osteoarthritis. Osteoarthritis Cartilage, 23(10), 1627-1638. http://dx.doi.org/10.1016/j.joca.2015.05.009

Chubinskaya, S., \& Wimmer, M. A. (2013). Key Pathways to Prevent Posttraumatic Arthritis for Future Molecule-Based Therapy. Cartilage, 4(3 Suppl), 13S-21S. http://dx.doi.org/10.1177/1947603513487457

Elain, G., Jeanneau, K., Rutkowska, A., Mir, A. K., \& Dev, K. K. (2014). The selective anti-IL17A monoclonal antibody secukinumab (AIN457) attenuates IL17A-induced levels of IL6 in human astrocytes. Glia, 62(5), 725-735. http://dx.doi.org/10.1002/glia.22637

Fahy, N., Farrell, E., Ritter, T., Ryan, A. E., \& Murphy, J. M. (2015). Immune modulation to improve tissue engineering outcomes for cartilage repair in the osteoarthritic joint. Tissue Eng Part B Rev, 21(1), 55-66. http://dx.doi.org/10.1089/ten.teb.2014.0098

Gerstenfeld, L. C., Cullinane, D. M., Barnes, G. L., Graves, D. T., \& Einhorn, T. A. (2003). Fracture healing as a post-natal developmental process: molecular, spatial, and temporal aspects of its regulation. J Cell Biochem, 88(5), 873-884. http://dx.doi.org/10.1002/jcb.10435

Gibon, E., Lu, L., \& Goodman, S. B. (2016). Aging, inflammation, stem cells, and bone healing. Stem Cell Res Ther, 7, 44. http://dx.doi.org/10.1186/s13287-016-0300-9

Greene, M. A., \& Loeser, R. F. (2015). Aging-related inflammation in osteoarthritis. Osteoarthritis Cartilage, 23(11), 1966-1971. http://dx.doi.org/10.1016/j.joca.2015.01.008

Haseeb, A., \& Haqqi, T. M. (2013). Immunopathogenesis of osteoarthritis. Clin Immunol, 146(3), 185-196. http://dx.doi.org/10.1016/j.clim.2012.12.011

Herenius, M. M., Oliveira, A. S., Wijbrandts, C. A., Gerlag, D. M., Tak, P. P., \& Lebre, M. C. (2013). Anti-TNF therapy reduces serum levels of chemerin in rheumatoid arthritis: a new mechanism by which anti-TNF might reduce inflammation. PLoS One, 8(2), e57802. http://dx.doi.org/10.1371/journal.pone.0057802

Hill, A. D., Palmer, M. J., Tanner, S. L., Snider, R. G., Broderick, J. S., \& Jeray, K. J. (2014). Use of Continuous Passive Motion in the Postoperative Treatment of Intra-Articular Knee Fractures. J Bone Joint Surg Am, 96(14), e118. http://dx.doi.org/10.2106/JBJS.M.00534

Hu, F., Li, Y., Zheng, L., Shi, L., Liu, H., Zhang, X., ... Li, Z. (2014). Toll-like receptors expressed by synovial fibroblasts perpetuate Th1 and th17 cell responses in rheumatoid arthritis. PLoS One, 9(6), e100266. http://dx.doi.org/10.1371/journal.pone.0100266

Huang, K., Du, G., Li, L., Liang, H., \& Zhang, B. (2012). Association of chemerin levels in synovial fluid with the severity of knee osteoarthritis. Biomarkers, 17(1), 16-20. http://dx.doi.org/10.3109/1354750X.2011.634028

Hui, A. Y., McCarty, W. J., Masuda, K., Firestein, G. S., \& Sah, R. L. (2012). A systems biology approach to synovial joint lubrication in health, injury, and disease. Wiley Interdiscip Rev Syst Biol Med, 4(1), 15-37. http://dx.doi.org/10.1002/wsbm.157

Imamura, M., Ezquerro, F., Marcon Alfieri, F., Vilas Boas, L., Tozetto-Mendoza, T. R., Chen, J., Ozcakar, L., Arendt-Nielsen, L., \& Rizzo Battistella, L. (2015). Serum levels of proinflammatory cytokines in painful knee osteoarthritis and sensitization. Int J Inflam, 329792. http://dx.doi.org/10.1155/2015/329792

Inci, S., Aksan, G., \& Dogan, P. (2016). Chemerin as an independent predictor of cardiovascular event risk. Ther Adv Endocrinol Metab, 7(2), 57-68. http://dx.doi.org/10.1177/2042018816629894

Jiang, L., Bao, J., Zhou, X., Xiong, Y., \& Wu, L. (2013). Increased serum levels and chondrocyte expression of nesfatin-1 in patients with osteoarthritis and its relation with BMI, hsCRP, and IL-18. Mediators Inflamm, 2013, 631251. http://dx.doi.org/10.1155/2013/631251 
Jin, X., Beguerie, J. R., Zhang, W., Blizzard, L., Otahal, P., Jones, G., \& Ding, C. (2015). Circulating C reactive protein in osteoarthritis: a systematic review and meta-analysis. Ann Rheum Dis, 74(4), 703-710. http://dx.doi.org/10.1136/annrheumdis-2013-204494

Kallaur, A. P., Oliveira, S. R., Colado Simao, A. N., Delicato de Almeida, E. R., Kaminami Morimoto, H., Lopes, J., ... Reiche, E. M. (2013). Cytokine profile in relapsingremitting multiple sclerosis patients and the association between progression and activity of the disease. Mol Med Rep, 7(3), 1010-1020.

Kapoor, M., Martel-Pelletier, J., Lajeunesse, D., Pelletier, J. P., \& Fahmi, H. (2011). Role of proinflammatory cytokines in the pathophysiology of osteoarthritis. Nat Rev Rheumatol, 7(1), 33-42. http://dx.doi.org/10.1038/nrrheum.2010.196

Katz, L. H., Kopylov, U., Fudim, E., Yavzori, M., Picard, O., Ungar, B., ... Chowers, Y. (2014). Expression of IL-2, IL-17 and TNF-alpha in patients with Crohn's disease treated with anti-TNF antibodies. Clin Res Hepatol Gastroenterol, 38(4), 491-498. http://dx.doi.org/10.1016/j.clinre.2014.01.010

Konttinen, Y. T., Sillat, T., Barreto, G., Ainola, M., \& Nordstrom, D. C. (2012). Osteoarthritis as an autoinflammatory disease caused by chondrocyte-mediated inflammatory responses. Arthritis Rheum, 64(3), 613-616. http://dx.doi.org/10.1002/art.33451

Kramer, W. C., Hendricks, K. J., \& Wang, J. (2011). Pathogenetic mechanisms of posttraumatic osteoarthritis: opportunities for early intervention. Int J Clin Exp Med, 4(4), 285-298.

Lieberthal, J., Sambamurthy, N., \& Scanzello, C. R. (2015). Inflammation in joint injury and post-traumatic osteoarthritis. Osteoarthritis Cartilage, 23(11), 1825-1834. http://dx.doi.org/10.1016/j.joca.2015.08.015

Liu, Y., Peng, H., Meng, Z., \& Wei, M. (2015). Correlation of IL-17 Level in Synovia and Severity of Knee Osteoarthritis. Med Sci Monit, 21, 1732-1736. http://dx.doi.org/10.12659/MSM.893771

Loi, F., Cordova, L. A., Pajarinen, J., Lin, T. H., Yao, Z., \& Goodman, S. B. (2016). Inflammation, fracture and bone repair. Bone, 86, 119-130. http://dx.doi.org/10.1016/j.bone.2016.02.020

Luangsay, S., Wittamer, V., Bondue, B., De Henau, O., Rouger, L., Brait, M., ... Parmentier, M. (2009). Mouse ChemR23 is expressed in dendritic cell subsets and macrophages, and mediates an anti-inflammatory activity of chemerin in a lung disease model. $J$ Immunol, 183(10), 6489-6499. http://dx.doi.org/10.4049/jimmunol.0901037

Lubberts, E., Joosten, L. A., van de Loo, F. A., van den Gersselaar, L. A., \& van den Berg, W. B. (2000). Reduction of interleukin-17-induced inhibition of chondrocyte proteoglycan synthesis in intact murine articular cartilage by interleukin-4. Arthritis Rheum, 43(6), 1300-1306. http://dx.doi.org/10.1002/1529-0131(200006)43:6<1300::AID-ANR12>3.0.CO;2-D

Mariani, F., \& Roncucci, L. (2015). Chemerin/chemR23 axis in inflammation onset and resolution. Inflamm Res 64(2), 85-95. http://dx.doi.org/10.1007/s00011-014-0792-7

Olson, S. A., Horne, P., Furman, B., Huebner, J., Al-Rashid, M., Kraus, V. B., \& Guilak, F. (2014). The role of cytokines in posttraumatic arthritis. $J$ Am Acad Orthop Surg, 22(1), 29-37. http://dx.doi.org/10.5435/JAAOS-22-01-29

Onishi, R. M., \& Gaffen, S. L. (2010). Interleukin-17 and its target genes: mechanisms of interleukin-17 function in disease. Immunology, 129(3), 311-321. http://dx.doi.org/10.1111/j.1365-2567.2009.03240.x

Pawlowska, J., Mikosik, A., Soroczynska-Cybula, M., Jozwik, A., Luczkiewicz, P., ...Bryl, E. (2009). Different distribution of CD4 and CD8 T cells in synovial membrane and peripheral blood of rheumatoid arthritis and osteoarthritis patients. Folia Histochem Cytobiol, 47(4), 627-632.

Raychaudhuri, S. P. (2013). Role of IL-17 in psoriasis and psoriatic arthritis. Clin Rev Allergy Immunol, 44(2), 183-193. http://dx.doi.org/10.1007/s12016-012-8307-1

Reinert-Hartwall, L., Honkanen, J., Salo, H. M., Nieminen, J. K., Luopajarvi, K., Harkonen, T., ... Group D. S. (2015). Th1/Th17 plasticity is a marker of advanced beta cell autoimmunity and impaired glucose tolerance in humans. J Immunol, 194(1), 68-75. http://dx.doi.org/10.4049/jimmunol.1401653

Roeleveld, D. M., \& Koenders, M. I. (2015). The role of the Th17 cytokines IL-17 and IL-22 in Rheumatoid Arthritis pathogenesis and developments in cytokine immunotherapy. Cytokine, 74(1), 101-107. http://dx.doi.org/10.1016/j.cyto.2014.10.006

Ruiz-Romero, C., \& Blanco, F. J. (2010). Proteomics role in the search for improved diagnosis, prognosis and 
$\begin{array}{lllll}\text { treatment of } \quad \text { osteoarthritis. } & \text { Osteoarthritis } & \text { Cartilage, } & \text { 18(4), }\end{array}$ http://dx.doi.org/10.1016/j.joca.2009.11.012

Sexton, M., Cudaback, E., Abdullah, R. A., Finnell, J., Mischley, L. K., Rozga, M., ... Stella, N. (2014). Cannabis use by individuals with multiple sclerosis: effects on specific immune parameters. Inflammopharmacology, 22(5), 295-303. http://dx.doi.org/10.1007/s10787-014-0214-z

Sharif, M., Shepstone, L., Elson, C. J., Dieppe, P. A., \& Kirwan, J. R. (2000). Increased serum C reactive protein may reflect events that precede radiographic progression in osteoarthritis of the knee. Ann Rheum Dis, 59(1), 71-74. http://dx.doi.org/10.1136/ard.59.1.71

Singh, S., Kumar, D., \& Sharma, N. R. (2014). Role of hyaluronic Acid in early diagnosis of knee osteoarthritis. $J$ Clin Diagn Res, 8(12), LC04-07. http://dx.doi.org/10.7860/jcdr/2014/11732.5342

Tanabe, S., \& Yamashita, T. (2014). Repulsive guidance molecule-a is involved in Th17-cell-induced neurodegeneration in autoimmune encephalomyelitis. Cell Rep, 9(4), 1459-1470. http://dx.doi.org/10.1016/j.celrep.2014.10.038

Tanasescu, C., Balanescu, E., Balanescu, P., Olteanu, R., Badea, C., Grancea, C., ... Georgescu, A. (2010). IL-17 in cutaneous lupus erythematosus. Eur $J$ Intern Med, 21(3), 202-207. http://dx.doi.org/10.1016/j.ejim.2010.03.004

Vaananen, T., Koskinen, A., Paukkeri, E. L., Hamalainen, M., Moilanen, T., Moilanen, E., \& Vuolteenaho, K. (2014). YKL-40 as a novel factor associated with inflammation and catabolic mechanisms in osteoarthritic joints. Mediators Inflamm, 215140. http://dx.doi.org/10.1155/2014/215140

Valcamonica, E., Chighizola, C. B., Comi, D., De Lucia, O., Pisoni, L., Murgo, A., ... Meroni, P. L. (2014). Levels of chemerin and interleukin 8 in the synovial fluid of patients with inflammatory arthritides and osteoarthritis. Clin Exp Rheumatol, 32(2), 243-250.

van Baarsen, L. G., Lebre, M. C., van der Coelen, D., Aarrass, S., Tang, M. W., ... Tak, P. P. (2014). "Heterogeneous expression pattern of interleukin 17A (IL-17A), IL-17F and their receptors in synovium of rheumatoid arthritis, psoriatic arthritis and osteoarthritis: possible explanation for nonresponse to anti-IL-17 therapy?" Arthritis Res Ther, 16(4), 426. http://dx.doi.org/10.1186/s13075-014-0426-z

Vermi, W., Riboldi, E., Wittamer, V., Gentili, F., Luini, W., Marrelli, S., ... Sozzani, S. (2005). Role of ChemR23 in directing the migration of myeloid and plasmacytoid dendritic cells to lymphoid organs and inflamed skin. $J$ Exp Med, 201(4), 509-515. http://dx.doi.org/10.1084/jem.20041310

Wojdasiewicz, P., Poniatowski, L. A., \& Szukiewicz, D. (2014). The role of inflammatory and anti-inflammatory cytokines in the pathogenesis of osteoarthritis. Mediators Inflamm, 2014, 561459. http://dx.doi.org/10.1155/2014/561459

Yang, L., Bai, L., Wei, F., Liu, Y., Sun, L., Wang, W., ... Wang, Y., (2015). Elevated autoantibodies against interleukin-17F correlate with disease activity in patients with early rheumatoid arthritis. Int J Rheum Dis.

Yu, P., Shen, F., Zhang, X., Cao, R., Zhao, X., Liu, P., ... Zhang, H. (2012). Association of single nucleotide polymorphisms of IL23R and IL17 with ulcerative colitis risk in a Chinese Han population. PLoS One, 7(9), e44380. http://dx.doi.org/10.1371/journal.pone.0044380

Zheng, Y., Sun, L., Jiang, T., Zhang, D., He, D., \& Nie, H. (2014). TNFalpha promotes Th17 cell differentiation through IL-6 and IL-1beta produced by monocytes in rheumatoid arthritis. J Immunol Res, 2014, 385352. http://dx.doi.org/10.1155/2014/385352

Zhuo, Q., Yang, W., Chen, J., \& Wang, Y. (2012). Metabolic syndrome meets osteoarthritis. Nat Rev Rheumatol, 8(12), 729-737. http://dx.doi.org/10.1038/nrrheum.2012.135

\section{Copyrights}

Copyright for this article is retained by the author(s), with first publication rights granted to the journal.

This is an open-access article distributed under the terms and conditions of the Creative Commons Attribution license (http://creativecommons.org/licenses/by/4.0/). 